\title{
التنازع عند البصريين والكوفيين (دراسة نحوية مقارنة)
}

\author{
نور حليمة السعدية \\ قسم تعليم اللغة العربية في كلية التربية بجامعة السنة الإسلامية ديلي سردانج \\ شارع ميدان-تانجونج موراوا كيلو متر ب ال، حي درمو، قرية باغون ساري، تانجونج موراوا، ديلي سردانج \\ Nuha_alqosimi93@yahoo.com
}

التجريد: قد ورد في كتب النحو كثير من اختلافات النحويين، من أشهرها الاختلاف بين البصريين والكوفيين. حيث أنهم قد اختلفوا في باب التنازع، رأى البصريون أن إعمال ثاني العاملين أولى من إعمال الأول ومعهم حجة. ورأى الكوفيون أن إعمال الأول أولى من إعمال الثاني وكذلك معهم حجة. من هذا الاختلاف رأت الباحثة بأن هذا المبحث مهم ليُتعمق فيه، حتى يُعرف كيف يكون الاختلاف والاتفاق بينهما، ولا شك في أن بعض آي القرآن كتبت بشكل التنازع، ولكي لايحدث اللحن في تطبيقه يوميا، فهو الهدف الرئيسي في وضع علم النحو الذي هو سعي إلى حفظ كلام الرحمن، ولاسيما من كان مشغولا بعلم النحو. نتائج هذا البحث هي أن بين هذين المذهبين بعض الاختلاف في التنازع، وهو في ست نقاط منها الاختلاف في أولى الفعل بالعمل، والاتفاق في أربع نقاط منها جواز إعمال واحد من العاملين، وغير ذلك من الاختلاف مما يترتب على أثر إعمال الفعل الأول كان أم الثاني كالإضمار والحذف والعطف والفصل. ومسألة التنازع هي محل الخلاف إلى اليوم. الكلمات المفتاحية: التنازع، البصريون، الكوفيون، المقارنة

مقدمة - مقد

إن اللغة العربية هي اللغة الاتصالية واللغة الدينية للمسلمين، لأن المصادر الأصلية لهذا الدين باللغة العربية، قال عمر بن الخطّاب رضي الله عنه: "تعلّموا العبية فإنها من دينكم". ' وإن أفضل مارغب وتعلق به الطالب معرفة لغة العرب، هي لأنّ العربية هي اللغة التي اختارها الله لهذا الدين، وأشار الله بتعلم اللغة العربية في كتابه الكريم، وأنزل القرآن الكريم بهذه اللغة: "(إنا أنزلناه

محمد بن علي بن أحمد بن عمر بن يعلى، أبو عبد الله، بدر الدين البعليّ، المنهج القويم في اختصار 》اقتضاء

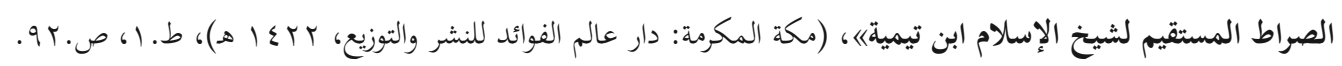


قرآنا عربيا لعلكم تعقلون)"، فهي إحدى اللغات الرسمية في هيئة الأمم المتحدة، وهي اللغة السادسة في العالم، يتحدث بها أكثر من ·. . مليون ناس.

ومن أهم علوم العربية التي اهتم بها العرب والمسلمون على مر العصور، علم النحو والصرف، لما له من الأثر العظيم في تقويم اللسان، وصيانة اللغة، وفهم معاني الشعر، وتوجيه معاني القرآن الكريم ومعرفة الحديث الشريف، فيكون استنباط الأحكام منهما على نحو سديد.؛ ووضع أبو الأسود الدؤلي علم النحوْْ إلى بواعث منها ترجع إلى الحرص الشديد على أداء نصوص الذكر الحكيم أداء فصيحا سليما إلى أبعد حدود السلامة والفصاحة، وخاصة بعد أن أخذ اللحن يشيع على الألسنة، وكان قد أخذ في الظهور منذ حياة الرسول -صلى الله عليه وسلم- وفي خلافة عمر -رضي الله عنه-. ولاسيما في زماننا اليوم وفي بلدنا هذا لقد لحن كثير من الناس مع أنهم من المتعلمين في المعاهد والجامعات، وكتب النحو متوفرة، فلا شك في أن هذه المشكلة تخالف الهدف في وضع علم النحو كما قاله عبد الرحمن الحنبلي الذي كان"...ثمرته صيانة اللسان عن الخطأ في كلام الله وكلام رسوله وكلام العرب". v فمن علم النحو مايسمى بالتنازع وهو لغة: التجاذب، وفي الاصطلاح: أن يتقدم فعلان متصرفان، أو اسمان يشبهانهما، أو فعل متصرف واسم يشبهه، ويتأخر عنهما معمول غير سببي

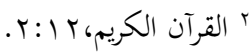

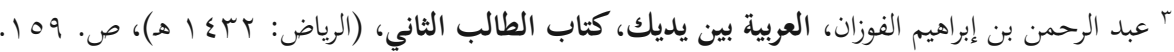
؛ البوصيري، العمدة في إعراب البردة قصيدة البوصيري، (دمشق: دار اليمامة للطباعة والنشر، د.س)، ط. ل، ج. ج.

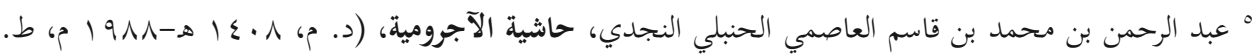

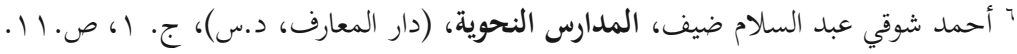
V عبد الرحمن بن محمد بن قاسم، نفس المكان. 
مرفوع، وهو مطلوب لكل منهما من حيث المعنى.^ مثله عباس حسن في كتابه: "وقف وتكلم الخطيب- نجد فعلين لا بد لكل منهما من فاعل، وليس في الكلام إلا اسم ظاهر واحد، يصلح أن يكون فاعلًا لأحدها، وهذا الاسم الظاهر هو: [الخطيب]، فأي الفعلين أحق بالفاعل؟ وإذا فاز به أحدهما، فأين فاعل الفعل الثاني؟ ومثال في ذلك كثير. فذهب البصريون والكوفيون على مذهبهم من حيث الاختلاف والاتفاق الذي سيأتي بيانه لاحقا.

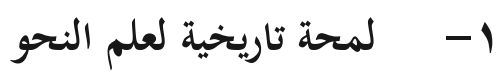

هذه اللمحة العظيمة في تاريخ العربية نقلت أكثرها من كتاب ضياء السالك الذي ذكره الشيخ الفاضل محمد عبد العزيز النجار.

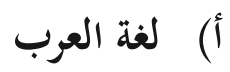

كان يسكن الجزيرة العربية شعبان عظيمان من شعوب الأمة العربية، هما: العدنانيون، وكانوا يسكنون بمكة وما والاها -ومنهم قريش-. والقحطانيون، وكانت منازلهم باليمن. وكانت لغة الشعبين عربية فصيحة، غير أنهما يختلفان في مدلول بعض الألفاظ واللهجات تختلف باختلاف القبائل." وكان العرب في هذه الآونة، يتكلمون العربية الصحيحة بالسليقة، على اختلاف قبائلهم ولهجاتهم، وكانوا قليلي الاتصال بمن حولهم من الأعاجم؛ فكان بين الفرس وعرب الجزيرة، والروم

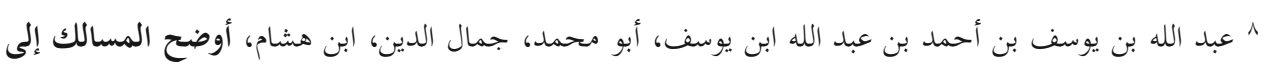

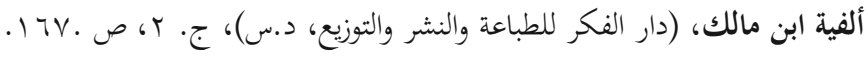

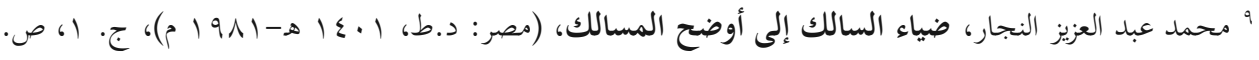


وعرب الشام شيء من الاتصال؛ دعا إلى أن يدخل بعض هؤلاء الجزيرة العربية، ويتعلمون اللغة،

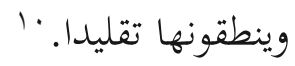

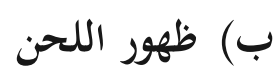

لما جاء الإسلام وانتشر خارج الجزيرة العربية، اضطرب العرب للاختلاط بغيرهم، وزاد اتصالهم بالأعاجم في سائر الأمصار، وتبادلوا معهم التجارة والمنافع؛ فأخذ الفساد يدب في تلك السليقة العربية، وظهر اللحن بين بعض العرب -علاوة على الدخلاء من الأعاجم- وساعد على ذلك: أن اللغة العربية لغة معربة، سرعان ما يتسرب إليها اللحن والفساد. وقد ظهر اللحن في عهد -النبي صلى الله عليه وسلم-؛ فقد روى أن رجلا لحن بحضرته، فقال: (أرشدوا أخاكم فقد ضلّ). ومر عمر ابن الخطاب على نفر يتمرنون على رمي السهام فوجدهم لا يحسنون، فأنبّأهم فقالوا له: إنا قوم متعلمين، فأفزعه ذلك وقال: والله لخطؤكم في لسانكم أشد عليّ من خطئكم في رميكم. وروى أن كاتبا لأبي موسى الأشعري -وكان واليا لعمر على البصرة- كتب رسالة على لسان أبي موسى إلى سيدنا عمر: من (أبو موسى) الأشعري إلى... فلما اطلع عمر عليها،" فكتب إليه عمر: "أَنْ قَنِّْْ كاتبك سوطا".

والأنكى من ذلك تسرب اللحن إلى قراءة الناس للقرآن، فقد قدم أعرابي في خلافة عمر فقال: "من يقرئني شيئا مما أنزل على محمد؟" فأقرأه رجل سورة براءة بهذا اللحن: "وأذان من الله ورسوله إلى الناس يوم الحج الأكبر أن الله بريء من المشركين ورسولِه ... " فقال الأعرابي: "إن يكن الله بريئا من رسوله، فأنا أبرأ منه" فبلغ عمر مقالة الأعرابي فدعاه فقال: يا أمير المؤمنين، إني

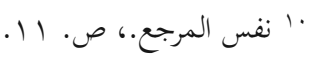

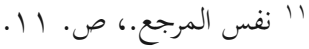

$$
\begin{aligned}
& \text { r" أحمد شوقي عبد السلام ضيف، المدارس النحوية، (د.م) دار المعارف، دس)، ج. 1ا، ص.11. }
\end{aligned}
$$


قدمت المدينة ... وقص القصة فقال عمر: "ليس هكذا يا أعرابي" فقال: "كيف هي يأمير المؤمنين؟" فقال: (أن اللََ بَرِيٌُ مِنَ الْهُشْرِكِينَ وَرَسُولُهُ) فقال الأعرابي: "وأنا أبرأ ممن برئُ الله ورسوله منهم". فأمر عمر ألا يقرئ القرآن إلا عالم باللغة. "' وهكذا انتشرت جرثومة اللحن.

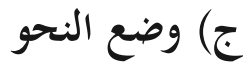

اختلفت الروايات عن المتقدمين فيمن أشار بوضع النحو، ومن ابتدأ وضعه. وكثر الحديث في ذلك؛ فمن قائل: إن علي بن أبي طالب أول من وضع النحو، وأنه دفع إلى أبي الأسود الدؤلي المتوفى سنة TV هجرية بصحيفة فيها: بسم الله الرحمن الرحيم، الكلام كله اسم وفعل وحرف ... إلخ. وأمره بتكميله. ومن قائل: إن أبا الأسود هو الذي ابتدأ هذا العمل بإشارة عمر رضي الله عنه- وقيل بإشارة زياد بن أبيه -وكان أبو الأسود معلم أولاده- وهو والي العراق وقتئذ، وقد لحظ انتشار اللحن. ويرى فريق أن أبا الأسود هو الذي بدأ ذلك بنفسه حين قالت له ابنته: يا أبت ما أحسنُ السماء! فقال نجومها. فقالت له: لم أرد أي شيء منها أحسن؟ إنما تعجبت من حسنها. فقال لها: قولي إذن: ما أحسنَ السماء! ثم دفعه ذلك إلى التفكير في وضع النحو، وابتدأ بباب التعجب.؛' وقال ابن قتيبة في المعارف: (أول من وضع العربية أبو الأسود) وقال ابن

$$
\text { حجر في الإصابة: (أول من ضبط المصحف ووضع العربية أبو الأسود). } 10
$$
د) متى وأين كان وضعه

عرفت مما سلف أن وضعه في الصدر الأول للإسلام، لأن علم النحو ككل قانون تتطلبه الحوادث، وتقتضيه الحاجات، ولم يك قبل الإسلام ما يحمل العرب على النظر إليه،

$$
\begin{aligned}
& \text { rا" سعيد بن محمد بن أحمد الأفغاني، من تاريخ النحو العببي، (ب.م: مكتبة الفلاح، ب.س.)، ج. 1، ص. .1. }
\end{aligned}
$$

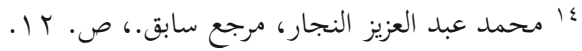

$$
\begin{aligned}
& \text { (0 } 10
\end{aligned}
$$


فإنهم في جاهليتهم غنيون عن تعرفه، لأنهم كانوا ينطقون عن سليقة جبلوا عليها، فيتكلمون في شؤونهم بدون إعمال فكر أو رعاية قانون كلامي يخضعون له، قانونهم ملكتهم التي خلقت فيهم، ومعلمهم بيئتهم المحيطة بهم، بخلافهم بعد الإسلام.17

\section{هـ) مذهبا البصريين والكوفيين وعلماءهم}

قد أنشئت مدينة البصرة في الجنوب الغربي من العراق؛ قريبا من بادية (نجد) سنة با

هـ، كما أنشئت مدينة الكوفة في الشمال منه سنة V هـ بعيدة عن البادية، وكلاهما في زمن الخليفة (سيدنا عمر بن خطاب). وكان بين أهل البصرة والكوفة تعصب قبلي، انقلب بعد إلى تعصب سياسي، ثم علمي، وقد هاجر إلى البصرة كثيرون من علماء الممالك المجاورة؛ ليتعلموا النحو على علمائها، وينقلوه إلى بلادهم. وبذلك انتشر المذهب البصري، وشجّع عليه خلفاء بني أمية. وتعتبر البصرة أول مدينة عنيت بالنحو واللغة وتدوينها، ووضع القواعد لهما. وقد سبقت غيرها بنحو قرن من الزمان. ويعتبر سيبويه وكتابه على رأس المذهب النحو البصري، وينقسم العلماء نحاة البصريين إلى عشر طبقات. قد اتخذ الكوفيون لهم مذهبا خاصا يضاهي مذهب البصريين وينافسه، واختلفوا معهم في كثير من المسائل؛ لأن بعض القواعد التي قعّدها البصريون جاء نتيجة استقراء ناقص؛ فقد كان الكوفيون أكثر رواية للشعر من البصريين. وعلى رأس المذهب الكوفي: أبو جعفر الرؤاسي، وتلميذه: الكسائي والفرّاء؛ وينقسم نحاة الكوفة إلى ست طبقات.

$$
\begin{aligned}
& 19
\end{aligned}
$$

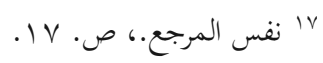


ومن خصائص المدرسة الكوفية أن الكوفيين يعتمدون بالمثال واحد، الأمثلة هي مناط القياس عند الكوفيين. يمتاز نحاة الكوفة بفهم العربية فهما لا يستند إلى فلسفات وتكنهات. النحو الكوفي أبعد ما يكون عن الأخذ بأسباب المنطق. حرص الكوفيين على الأخذ

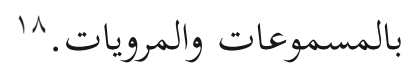

قد حدثت بين أصحاب المذهبين مناقشات وخلافات ومنازعات ومناظرات -ابتدأت هادئة بين الخليل من البصريين، والرؤاسي من الكوفيين. ثم اشتدت بين سيبويه والكسائي وأتباعها. وقد كان لهذه العصبية العلمية التي نشأت عن العصبية السياسية- أثر عظيم في خدمة العلم، والتسابق في تجليته. واستمر الخلاف إلى أواخر القرن الثالث الهجري. ثم خفت حدة النزاع والجدل، وتقارب المذهبان حين التقى الكوفيون بالبصريين في بغداد بعد قليل.19 والذي لا شك فيه، أن البصريين كانوا أكثر استنباطا وإنتاجا، وأوثق رواية من الكوفيين؛ لما ذكرنا أن الفصحاء من العرب كانوا يتردّدون على البصرة أكثر من الكوفة؛ لقرب الأولى منهم. وقد نضج النحو في البصرة قبل الكوفة بنحو مائة عام. وهذا لا يحول دون صواب رأي الكوفة في كثير من المسائل. ‘r وقد كان الكوفيون أكثر رواية للشعر من البصريين، وكانوا يستنبطون بعض القواعد بالقياس النظري من غير حاجة إلى شاهد. أما البصريون فكانوا لا يستجيبون لكل مسموع، ولا يقيسون على الشاذ، ولهذا كانوا أصح قياسا من الكوفيين. ومن هنا نشأ خلاف بين ^1 مهدي المخزومي، مدرسة الكوفة ومنهجها في دراسة اللغة والنحو، (بغداد: دار المعرفة، ع ع ا هـ-1900 م)،

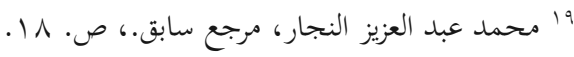

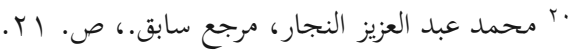


الفريقين في كثير من الفروع النحوية مبنية وموضحة في الكتب الأصل. ونسطتيع أن نجمل الفروق الأساسية بين المذهبين فيما يأتي:

1. البصريون حازمون متشددون في قبول ما يروى من الشعر، ولا يعترفون إلا ببعض القبائل العربية الموثوق بشعرها، وقد ذكرناها قريبا، ويقل عندهم التجويز وقلما يعتمدون على خبر

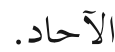

r. البصريون صارمون. معتدون بأنفسهم، والثقة بروايتهم، ويخطئون ما عداها من الروايات التي لم تثبت لديهم مهما كان مصدرها. r. البصريون يؤولون ما يخالف قواعدهم ولو كان عربيا فصيحا، ويتكلفون في ذلك عنتا، وإذا أعجزهم التأويل حكموا بشذوذه. ب

ومن أمثلة المسائل التي وقع فيها الخلاف: العطف على موضع (إنَّ) بالرفع قبل تمام الخبر؛ وقوع الفعل الماضي حالا؛ إظهار (أنْ) المصدرية بعد (لكي) و(بعد) حتى؛ ترخيم المضاف؛rr إعمال التنازع؛ وغير ذلك.

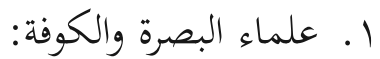
أ. ـبقات البصريين

1) الطبقة الأولى: نصر بن عاصم الليثي (ت 19 هـ)، عنبسة بن معدان الفيل المهري (لايعرف تاريخ وفاته)، عبد الرحمن بن هرمز أبو داود الأعراج (ت V V ا هـ)، أبو سليمان يحيى بن يعمر العدواني (ت 9 ب ا هـ)

$$
\text { rr "r نفس المرجع.، ص. • •T. }
$$


Y) الطبقة الثانية: عبد الله بن أبي إسحاق الحضرمي (ت V V I هـ)، عيسى بن عمر الثقفي

$$
\text { (ت } 1 \text { (ت هـ)، أبو عمرو بن العلاء (ت } 7 \text { (ت هـ) }
$$

r) الطبقة الثالثة: الأخفش الأكبر (ت VV Iه)، الخليل بن أحمد (ت V V هـ)، يونس بن

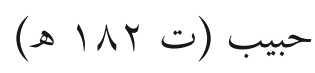

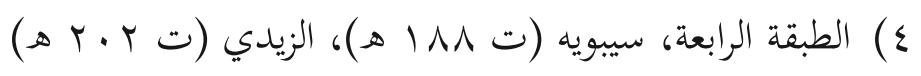

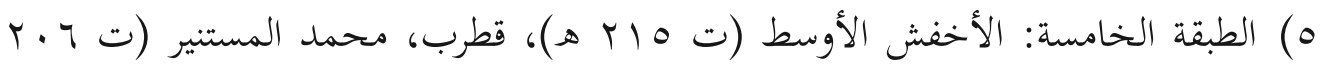

T) الطبقة السادسة: الجرمي، أبو عمر صالح بن إسحق الجرمي (ت مبr هـ)، التوزي (ت

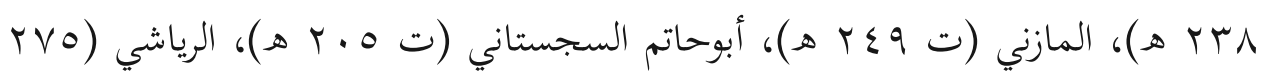

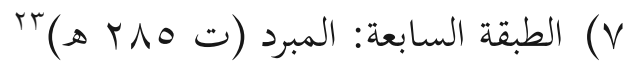

يعد ابن أبي إسحق الحضرمي أول النحاة البصريين بالمعنى الدقيق لهذه الكلمة، ويتبعه في هذه الأولية المبكرة جيل من تلاميذه في مقدمتهم عيسى بن عمر، وأبو عمرو بن العلاء، ويونس بن حبيب. ؟ ب. طبقات مدرسة الكوفة

rrr نبيهة بنت عبد الله باخشوين، أصول النحو وتاريخه، (الرسالة، جامعة أم القرى، مملكة العربية السعودية)، ص.

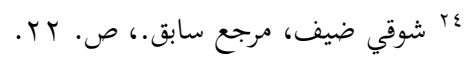


1) الطبقة الأولى: الرؤاسي، أبو جعفر محمد بن الحسن لقب الرؤاسي لكبر رأسه، ألّف

كتاب (الفيصل) في النحو، توفي في الكوفة في عهد الرشيد. ومعاذ الهراء (ت

$$
(\infty) V
$$

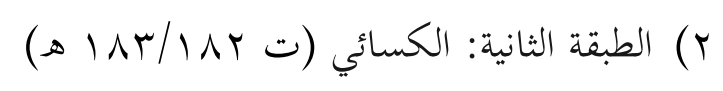

r) الطبقة الثالثة: الأحمر، أبو الحسن علي بن الحسن المعروف بالأحمر (ت ع9 19 هـ)، الفراء، أبو زكريا يحيى بن زياد لقب بالفراء لأنه كان يفري الكلام (ت V.

$$
\begin{aligned}
& \text { هـ)، اللحياني، أبو الحسن علي بن المبارك من بني الحيان (ت · ب هـ) } \\
& \text { \&) الطبقة الرابعة: ابن سعدان، أبو جعفر الضرير محمد بن سعدان (ت آY هـ)، } \\
& \text { الطوال، أبو عبد الله محمد بن أحمد قدم بغداد (ت r r ب ه)، ابن قادم، أبو } \\
& \text { جعفر محمد بن عبد الله بن قادم توفي ببغداد سنة اOY هـ. } \\
& \text { ه) الطبقة الخامسة: ثعلب (ت 19 هـ) }
\end{aligned}
$$

قال القفطي في إنباه الرواة: (يقول أهل الكوفة: لنا ثلاثة فقهاء في نسق، لم ير الناس مثلهم؛ أبو حنيفة، وأبو يوسف، ومحمد بن الحسن. ولنا ثلاثة نحويون كذلك: علي بن حمزة الكسائي،

$$
\begin{aligned}
& \text { وأبو زكريا يحيى بن الفراء، وأبو العباس أحمد بن يحيى ثعلب. ror } \\
& \text { 1- - التنازع عند البصريين والكوفيين } \\
& \text { أ) تعريف الثنازع }
\end{aligned}
$$

باب الثنازع "ويسمى أيضًا باب الإعمال" بكسر الهمزة عند الكوفيين.بr لقد

عرّف العلماء تعريف التنازع بالتعاريف كثيرة. ولم يذكر سيبويه التنازع في كتابه

$$
\text { ro }
$$


باسمه، قال "هذا باب الفاعلين والمعمولين كل واحد منهما يفعل بفاعله مثل الذي يفعل به وما كان نحو ذلك"، وكذا المبرد إذ قال في المقتضب: هذا باب من إعمال الأول والثاني وهما الفعلان اللذان يعطف أحدهما على الآخر. وأما ابن هشام قال في كتابه: هذا باب التنازع في العمل ويسمى أيضا باب الإعمال. إذ لم يحدد العلماء مصطلح الثنازع بل تركوه في عناوين عامة حتى وصل تحديده إلى علماء القرون التالية فسمِّي التنازع أو الإعمال . rv

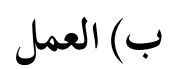

قد كتب الشيخ الفاضل أبو البركات كمال الدين الأنباري في كتابه

الإنصاف في مسائل الخلاف بين النحويين ووضع العنوان "القول في أولى

العاملين بالعمل في التنازع". إذ قد اتفق البصري والكوفي في إعمال كل من

المتنازعين، لكن اختلفا في أولى العاملين بالعمل. قال فضيلة الشيخ محمد عبد

العزيز النجار أن "إذا تنازع العاملان جاز إعمال أيهما شاء باتفاق (أي من

البصريين والكوفيين، فقد سمع عن العرب إعمال كل منهما). والخلاف بينهما

إنما هو المختار، لا في أصل الجواز)، واختار الكوفيون الأول لسبقه والبصريون

الأخير لقربه.^^ عند ابن مالك في كتابه شرح الكافية الشافية أن المختار عند

\footnotetext{
بr خالد بن عبد الله بن أبي بكر بن محمد الجرجاويّ الأزهري، شرح التصريح على التوضيح أو التصريح بمضمون

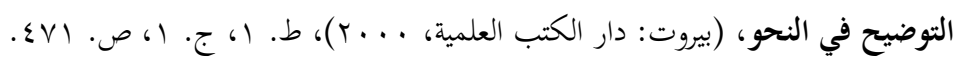

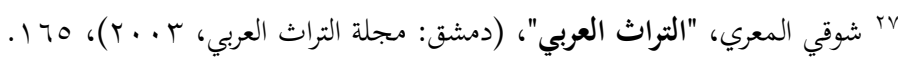

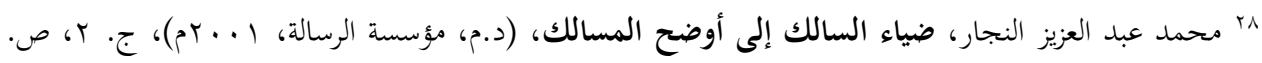


البصريين إعمال الثاني، وعند الكوفيين إعمال الأول.وْ ذهب الكوفيون في

إعمال الفعلين، نحو "أَكْرَمنبي وأكرمتُ زيدًا، وأكرمتُ وأكرمنبي زيدُّ" إلى أن

إعمال الفعل الأول أولى، وذهب البصريون إلى أن إعمال الفعل الثاني أولى.جr

أي رأى البصريون أن إعمال ثاني العاملين أولى من إعمال الأول منهما لثلاث

حجج: الأولى: أنه أقرب إلى المعمول. الثانية: أنه يلزم على إعمال الأول منهما

الفصل بين العامل -وهو المتقدم- ومعموله -وهو الاسم الظاهر- بأجنبي من

العامل، وهو ذلك العامل الثاني، ومع أن الفصل بين العامل والمعمول مغتفر في

هذا الباب للضرورة التي ألجات إليه، فهو خلاف الأصل على الأقل. الثالثة: أنه

يلزم على إعمال العامل الأول في لفظ المعمول أن تعطف على الجملة الأولى

-وهي جملة العامل الأول مع معموله- قبل تمامها، والعطف قبل تمام

المعطوف عليه خلاف الأصل. رأى الكوفيون أن إعمال الأول أولى من إعمال

الثاني لعلتين: الأولى: أنه أسبق وأقدم ذكرا. والثانية: أنه يترتب على إعمال

العامل الثاني في لفظ المعمول المذكور أن تضمر ضميرا في العامل الأول

منهما، فيكون في الكلام الإضمار قبل الذكر، وهو غير جائز عندهم، وخلاف

الأصل عند البصريين. ولكل فريق من الفريقين مستند من السماع عن العرب. "r

9r محمد بن عبد الله، ابن مالك الطائي الجياني، أبو عبد الله، جمال الدين، شرح الكافية الشافية، (د.م. جامعة أم

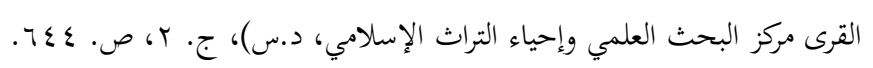

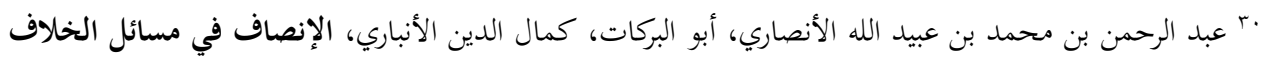

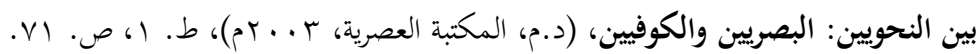

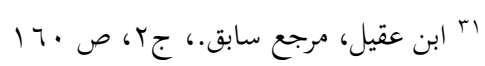


قال الناظم ابن الحاجب: "ويختار البصريون إعمال الثاني، والكوفيون

الأول"، ثم شرحه الرضي: أي البصريون يقولون: المختار إعمال الثاني مع تجويز

إعمال الأول. وكذا الكوفيون: يختارون إعمال الأول مع تجويز إعمال الثاني.

وإنما اختار البصريون إعمال الثاني لأنه أقرب الطالبين إلى المطلوب فالأولى أن

يستبد به دون الأبعد. وقال الكوفيون: إعمال الأول أولى لأنه أول الطالبين،

واحتياجه إلى ذلك المطلوب أقدم من احتياجه الثاني.rّ قوله: "والثان من

المتنازعين أولى بالعمل من الأول عند أهل البصرة لقربه" عللت أيضا أولوية

الثاني بسلامته من العطف قبل تمام المعطوف عليه ومن الفصل بين العامل

والمعمول بأجنبي وإن اغتفر ذلك هنا للضرورة. قوله: "وهو أن الأول أولى

لسبقه" ثم كل مما يليه أولى من لاحقه للعلة المذكورة. بّ الكوفيون احتجوا بأن

قالوا: الدليل على أن إعمال الفعل الأول أولى النقل والقياس. أما النقل فقد جاء

ذلك عنهم كثيرا، قال امرؤ القيس: فلو أن ما أسعى لأدنى معيشة كفاني،

ولم أطلب قليلٌ من المال. فأعمل الفعل الأول، ولو أعمل الثاني لنصب

"قليلا". وقال رجل من بني أسد: وقد نغى بها ونرى عصورا بها، يقتدننا الخُردَ

والخِدالاً، فأعمل الأول، ولذلك نصب (الخرد والخدال)، ولو أعمل الفعل

$$
\text { الثاني لقال (تقتادنا الخردُ والخدال) بالرفع. عُ }
$$

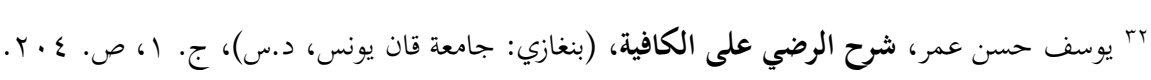

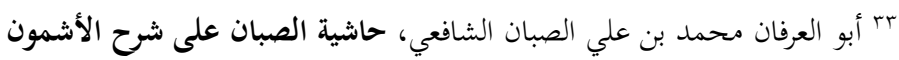

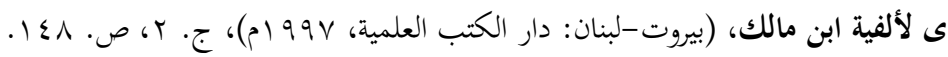

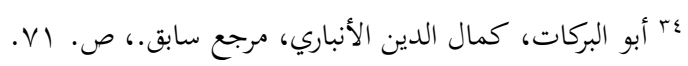


أما القياس فهو أن الفعل الأول سابق الفعل الثاني، وهو صالح للعمل كالفعل الثاني، إلا أنه لما كان مبدوءا كان إعماله أولى، لقوة الإبتداء والعناية به. •r والثانِ أولى عند أهل البَصْرَه ... واختار عكسا غيرهم ذا أَسْرَه، عمل كل "واحد" منها مسموع، والخلاف في الترجيح. فقال البصريون: إعمال الثاني أرجح لقربه، وقال الكوفيون: إعمال الأول أرجح "لسبقه"، وقال بعض النحويين: يتساويان. وفصل أبو ذر الخشني فقال: إن كان إعمال الثاني يؤدي إلى الإضمار في الأول فيختار إعمال الأول، وإلا فيختار إعمال الثاني.جr

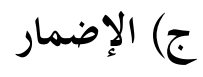
يترتب على هذا الاختيار والمفاضلة ما يلي: أولا: عند اختيار الأول -وهو رأي الكوفيين- يضمر في العوامل المتأخرة كل ما تحتاجه من ضمائر مرفوعة ومنصوبة ومجرورة. ثانيا: عند اختيار الأخير -وهو رأى البصريين- يضمر في العوامل السابقة ما تحتاجه من ضمير للرفع فقط -فاعل أو نائب فاعل- ويصرف النظر عما تحتاجه من ضمائر منصوبة أو مجرورة.rv إن أعمل الأول وجب الإضمار في الثاني فيقول يحسن ويسيئان ابناك ومثله بغى واعثديا عبداك، وإن أعمل الثاني في هذا المثال فيقول بغيا واعتدى عبداك ولا يجوز ترك الإضمار فلا تقول يحسن ويسيء ابناك ولا بغى واعتدى عبداك لأن

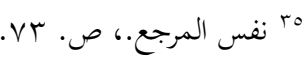
بr أبو محمد بدر الدين حسن بن قاسم بن عبد الله بن عليّ المرادي المصري المالكي، توضيح المقاصد والمسالك

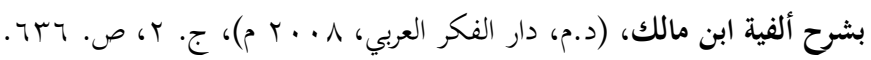

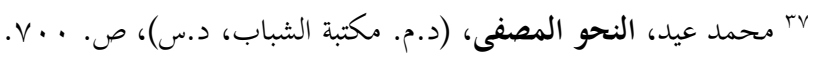


تركه يؤدي إلى حذف الفاعل، والفاعل ملتزم الذكر وأجاز الكسائي ذلك على الحذف بناء على مذهبه في جواز حذف الفاعل وأجازه الفراء على توجه العاملين معا إلى الاسم الظاهر وهذا بناء منهما على منع الإضمار في الأول عند إعمال الثاني فلا تقول يحسنان ويسيء ابناك وهذا الذي ذكرناه عنهما هو المشهور من مذهبهما في هذه المسألة.^^ تقدم أنه إذا أعمل أحد العاملين في الظاهر وأهمل الآخر عنه أعمل في ضميره ويلزم الإضمار إن كان مطلوب الفعل مما يلزم ذكره كالفاعل أو نائبه ولا فرق في وجوب الإضمار حيئذ بين أن يكون المهمل الأول أو الثاني فتقول يحسنان ويسيء ابناك ويحسن ويسيئان ابناك. من هذا الباب العامل الذي أُهمل ولم يسلّط على الاسم الظاهر كقولنا: أعطى وسألتُ الله...ففي (أعطى) ضمير مفسر بما بعده، وهذا أجازه البصريون ولم يجزه الكوفيون تجنبا لإضمار قبل ذكر المفسر. •؛ فإن أعملنا الأول في المتنازع فيه أعملنا الأخير في ضميره، (سواء أكان مرفوعا أم منصوبا أم مجرورا) نحو: قام وقعد، أو: وضربتُهما، أو: ومررتُ بهما أخواك. وبعضهم يجيز حذف غير المرفوع، لأنه فضلة، كقوله: بعكاظ يُعشي الناظرين إذا هم لمحوا شعاعُه، تنازع "يعشي ولمحوا" العمل في (شعاعه)، وقد أعمل الأولى ورفع شعاعه على أنه فاعل، وأعمل الثاني في ضميره فنصبه على أنه مفعول به، ثم حذف لأنه فضلة، ولو ذكره لقال: إذا هم لمحوا شعاعَه وهذا الحذف لضرورة الشعر عند البصريين. وإن أعملنا الثاني

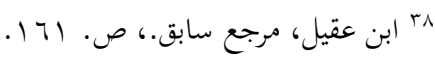

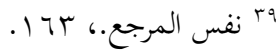

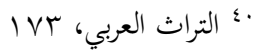


فإن احتاج الأول لمرفوع، فالبصريون يضمرونه لامتناع حذف العمدة، ولأن الإضمار قبل الذكر قد جاء في غير هذا الباب."§

قد حكى ابن كيسان أن الكوفيين وافقوا البصريين في جواز تقديم الضمير على مفسره المبدل منه نحو: "يقومون الزيدون" و"رأيتهم العمرين" مع أن البدل تابع، وتأخير التابع واجب. وأعمل المهمل في ضمير ما ... تنازعاه والتزم ما التزما. كيحسنان ويسيء ابناكا ... وقد بغى واعتديا عبداكا. "وأعمل المهمل"منها وهو الذي لم يتسلط على الاسم الظاهر مع توجهه إليه في المعنى "في ضمير ما تنازعاه والتزم" في ذلك "ما التزما" من مطابقة الضمير للظاهر، ومن امتناع حذف هذا الضمير حيث كان عمدة؛ وسواء في ذلك كان الأول هو المهمل "كيحسنان ويسيء ابناكا" أم الثاني "و" ذلك نحو: "قد بغى واعتديا عبداكا" وهذا المثال الثاني متفق على جوازه، والأول منعه الكوفيون؛ لأنهم يمنعون الإضمار قبل الذكر في هذا الباب؛ فذهب الكسائي ومن وافقه إلى وجوب حذف الضمير من الأول والحالة هذه- للدلالة عليه، تمسكا بظاهر قوله: تعفق بالأرطى لها وأرادها، رجال فبذت نبلهم وكليب. وقال الفراء: إن اتفق العاملان في طلب المرفوع فالعمل لهما، ولا إضمار، نحو: "يحسن ويسيء ابناكا"؛ وإن اختلفا أضمرته مؤخرا، نحو: "ضربني وضربت زيدا هو"، والمعتمد ما عليه البصريون، وهو ما سبق؛ لأن العمدة يمتنع حذفها، ولأن الإضمار قبل الذكر قد جاء في غير هذا الباب، نحو: "ربه

$$
\text { " محمد عبد العزيز النجار، مرجع سابق، ج. r، ص. -11 }
$$


رجلا"، وقد سمع أيضا في هذا الباب، من ذلك ما حكاه سيبويه من قول بعضهم:

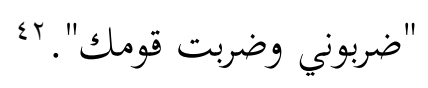

د) الحذف

والحذف من أثثر الإعمال أيضا كما قال الرضي. ومن النُحاة من أجاز حذفه، إن

كان غيرَ ضميرِ رفعٍ، لأنهُ فضلة، وعليه قول الشاعر : بِعُكاظَ يُعْشي النَّاظِيد .... نَّ،

إذا هُمُ لَمَحُوا، شُعاعُه، "فإنان" تنازع اثنان، و"أعملنا الأول في المتنازع فيه" على

اختيار الكوفيين، "أعملنا الأخير في ضميره" مرفوعًا كان أو منصوبا أو مجرورًا،

"نحو: "قام وقعدا" أخواك"، "أو" قام "وضربتهما" أخواك، "أو" قام "ومررت بهما

أخواك، وبعضهم" كالسيرافي "يجيز حذف غير المرفوع" وهو المنصوب والمجرور

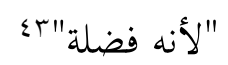

"وإن أعملنا الثاني" على اختيار البصريين "فإن احتاج الأول لمرفوع فالبصريون

يضمرونه" ولا يحذفونه "لامتنع حذف العمدة" عندهم. "و" إن لزم منه الإضمار قبل

$$
\text { الذكر، وهو عود الضمير على متأخر في اللفظ والرتبة.؟؟ }
$$

"جفوني ولم أجف الأخلاء إنني" ... لغير جميل من خليلي مهمل، فأعمل

الثاني، ونصب "الأخلاء" المنصوب على المفعولية، و"الأخلاء": جمع خليل

و"الجميل": الشيء الحسن، و "مهمل": اسم الفاعل من الإهمال، وهو الترك.

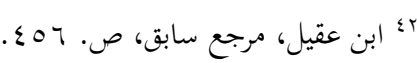

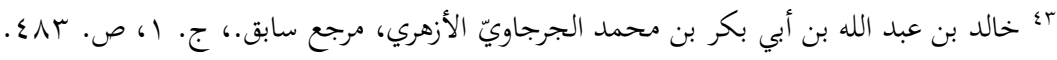

$$
\begin{aligned}
& \text { گ؛ نفس المرجع.، ج. ل، ص. عـــ. }
\end{aligned}
$$


"والكسائي وهشام" الضرير "والسهيلي" والكوفيون "يوجبون الحذف" للضمير

$$
\text { المرفوع على الفاعلية هربًا من الإضمار قبل الذكر. ه؛ }
$$

وأن أعملتَ الثانيَ في الظاهر، أعملتَ الأولَ في ضميره، إن كان مرفوعاً نحو:

"قاما وقعَد أخواك، اجتهدا فأكرمتُ أخوَيْك، وَقَفا فستلَّمتُ على أخويكَّ". وإن كان ضميرُهُ غير مرفوِع حذفتَهُ، نحو "اكرمتُ فَسُرَّ أخواك، أكرمتُ فشكرَ لي خالدُ، أكرمتُ وأكرَمني سعيدُ، مررتُ ومَرَّ بي علئُ." ولا يقال "أكرمتهما فَسُرَّ أخوالَك، أكرمتُهُ فشكر لي خالد، أكرمتُهُ وأكرمني سعيدُ، مررتُ به ومَّ بي عليَّ." وأمّا قول الشاعر إذا كُنْتَ تُرْضِيهِ وَيُرْيكَ صاحبُ ... جِهاراً، فَكُنْ في الْغَيْبِ أَحَظَ للعَهْدِ. بإظهار الضمير المنصوب في "تُضيه"، فضرورةٌ لا يحسُنُ ارتكابها عند الجمهور. وكان حقُُهُ ان يقول "إذا كنت تُرضي، ويُرضيكَ صاحبٌّ". وأجازَ ذلك بعضُ مُحَقّقي النّحاة. (وذهب الكسائيّ ومن تابعه الى أنه إذا أعمل الثاني في الظاهر، لم تُضمر الفاعل في الاول بل يكون فاعله محذوفاً لدلالة ما بعده عليه (لانه يُجيز حذف الفاعل اذا دل عليه دليل). فاذا قلت "اكرمني فسرّني زهيرُ"، فان جعلت زهيراً فاعلاً لسرّ، كان فاعل "أكرَ" (على رأى سيبويه والجمهور) ضميراً مستتراً يعود اليه. وعلى رأي الكسائي ومن وافقه يكون فاعل "اكرًّ" محذوفاً لدلالة ما بعده عليه. ويظهر اثر الخلاف في التثنية والجمع، فعلى رأي سيبويه يجب ان تقول (ان اعملت الثاني) "اكرماني فسرَّني صديقايَ، واكرموني فسرَّني اصدقائي". وتقول على مذهب الكسائي ومن تابعه "اكرمني فسرَّني صديقايً، واكرمني فسرَّي

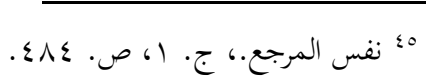


اصدقائي". فيكون الاسم الظاهر فاعلاً للثاني. ويكون فاعل الاول محذوفاً. وما قاله الكسائي ليس ببعيدٌ، لان العرب تستغني في كلامها عما يُعلم لو حُذف، ولو كان عمدة. ولهذا شواهلُ من كلامهم. اما لو أعمل الاول في الاسم الظاهر، فيجب بالاتفاق الإضمار في الثاني، نحو "اكرمني فسرَّاني صديقايَ، واكرمني فسرّوني اصدقائي". والذي دعا الكسائيّ إلى ما ذهب إليه، انه لو لم يحذف الفاعل، لوجب أن يكون ضميراً عائداً على الاسم الظاهر المتأخر لفظاً ورتبة، وذلك قبيح. وقال سيبويه ان عود الضمير على المتأخر أهون من حذف الفاعل، وهو عمدة، والحقّ أنَّ لكل وجهاً، وانّ الإضمار وتركه على حد سواء. وقد ورد في كلامهم ما يؤيد ما ذهب اليه الفريقان. فقول الشاعر جفوني ولم اجف الاخلاءً ... " شاهدٌ لسيبويه وقول الآخر تعفق بالارطى لها وأرادها ... رجالٌ، فبذَّت نبلَهم وكَليبٌ. (شاهدُ للكسائي فهو لا يُضمر في واحد من الفعلين. ولو اضمر في الأول واعمل الثاني لقال "تعفقوا بالارطى وأرادها رجال". ولو اضمر في الثاني واعمل الأول، لقال "تعفق

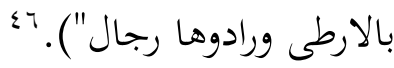

$$
\text { ه) النية }
$$

"تعفق بالأرطى لها وأرادها ... رجال" فبذت نبلهم وكليب"، "إذ لم يقل: تعفقوا" على تقدير إعمال الثاني، "ولا: أرادوه" على تقدير إعمال الأول، ويمكن أن يجاب عنه بأنه أعمل الثاني، ولم يقل "تعفقوا" على لفظ الجمع؛ لأنه يجوز أن

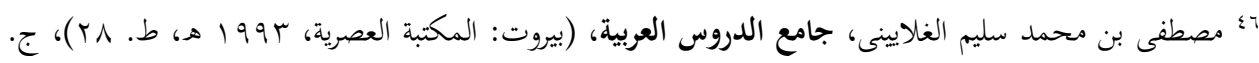


ينوي مفردًا على مذهب البصريين باعتبار تأويله بالمذكور. لغّ ويكون قد أضمر في

أحد الفعلين مفردا كما حكى سيبويه: "ضربني وضربتُ قومَك". م؛

تفصيلا من البيانات السابقة تستخرج النتيجة فيما يلي:

أ. الاختلاف عند علماء الكوفة والبصرة في التنازع وما يتعلق به

\begin{tabular}{|c|c|c|c|}
\hline آراء علماء البصرة & آراء علماء الكوفة & 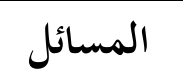 & 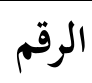 \\
\hline الفعل الثاني أولى بالعمل لقربه. & الفعل الأول أولى بالعمل لسبقه. & أولى العمل & 1 \\
\hline 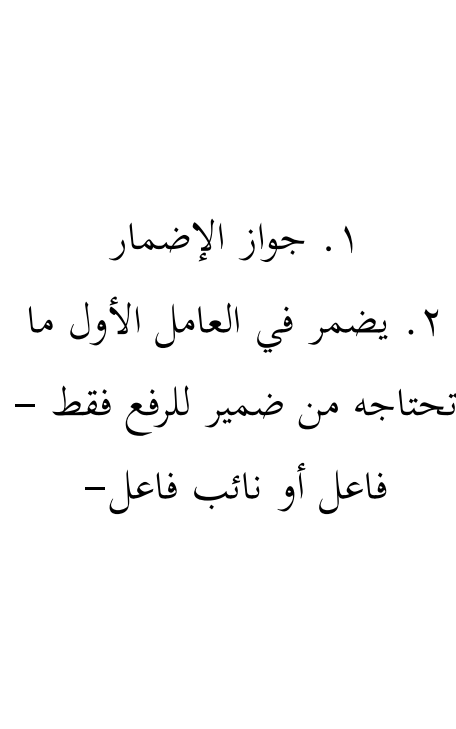 & 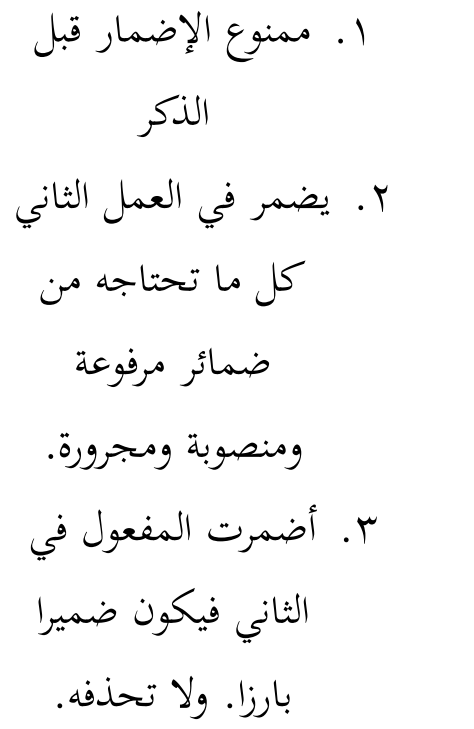 & الإضمار & r \\
\hline جواز حذف حذف الفضلة لامتناع. & ذجوب الكسائيّ ومن تابعه إلى لـفير المرفوع & الحذف & r \\
\hline اجتناب الفصل & جواز الفصل & 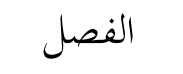 & $\varepsilon$ \\
\hline اجتناب العطف وسلامته منه & جواز العطف & العطف & 0 \\
\hline جواز نية الإفراد باعتبار تأويله & & النية & 7 \\
\hline
\end{tabular}

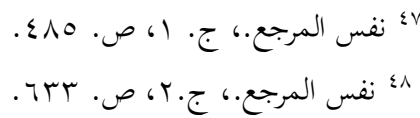


ب. الاتفاق بين علماء الكوفة والبصرة في التنازع

\begin{tabular}{|c|c|c|c|}
\hline آراء علماء البصرة & آراء علماء الكوفة & المسائل & 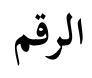 \\
\hline من جهة تعريف التنازع لم يختلف & الإعمال بكسر الهمزة عند & التعريف & 1 \\
\hline تجويز إعمال كل واحد من & تجويز إعمال كل واحد من & عوامل ع & r \\
\hline مستند على السماع والقياس & مستند على السماع والقياس & 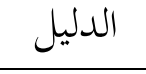 & $r$ \\
\hline جواز تقديم ضمير المفسر & جواز تقديم ضمير المفسر & المغسر & $\varepsilon$ \\
\hline
\end{tabular}

ختام

من خلال البيانات السابقة تبينت أن البصريين والكوفيين لا يختلفون مائة في المائة، ولا يتفقون تماما، إنما هؤلاء يختلفون في بعض النقاط ويتفقون في النقاط الأخرى. كما ذُكر سابقا أن بين هذين فريقين شيء من التنافس بل حتى التعصب. وتبين أن كلام العرب قد جاء يإعمال أول العاملين في لفظ المعمول المتأخر عنها، وإعمال العامل الثاني في لفظه أيضا، ومن إعمال العامل الأول الشواهد التي استدل بها الكوفيون، ومن إعمال الثاني الشواهد التي استدل بها البصريون، فليس لواحد من الفريقين أن يدعي أن الاستعمال العربي يؤيده وحده، لأن الاستعمال العربي يؤيد كل واحد منها، وكل ما هناك أنه يبقى سؤال، وهو هل العامل الأول أولى بالعمل لكونه متقدما وقد طلب المعمول قبل أن يطلبه الثاني، أم العامل الثاني أولى لكونه أقرب إلى المعمول ومجاورا له. وأما العامل الأول فهو مفصول من المعمول بالعامل الثاني على الأقل، ولا 
يرى أحد أن يحاول ترجيح إحدى هاتين القضيتين، فإن لكل منها مستندا من التعليل والقياس لا

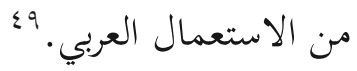

فالخلاصة أن المسألة الخلافية الرئيسية لباب التنازع هي مسألة الإعمال فقط، والاختلاف الذي يأتي بعد ذلك هو من أثر الاختلاف في الإعمال كالإضمار والحذف والفصل والعطف.

القرآن الكريم

ابن عقيل ، عبد الله بن عبد الرحمن العقيلي الهمداني المصري، شرح ابن عقيل على ألفية ابن

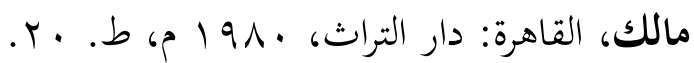

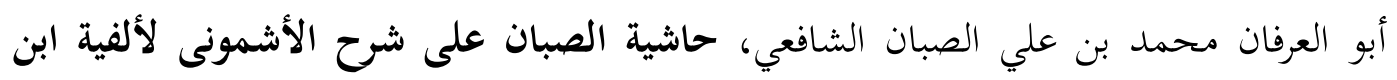
مالك، بيروت-لبنان: دار الكتب العلمية، و9 9 1م.

أبو محمد بدر الدين حسن بن قاسم بن عبد الله بن عليّ المرادي المصري المالكي، توضيح

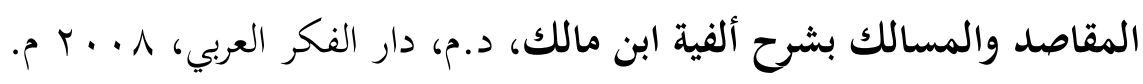

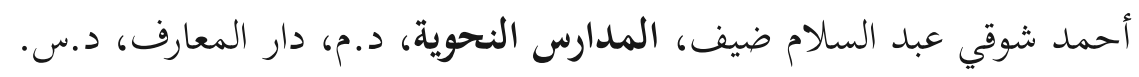

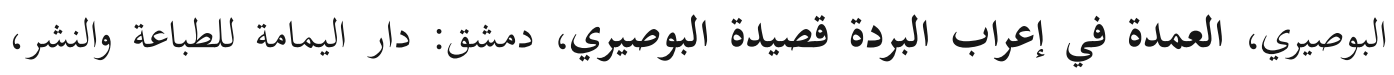

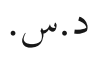
خالد بن عبد الله بن أبي بكر بن محمد الجرجاويّ الأزهري، شرح التصريح على التوضيح أو الو الته

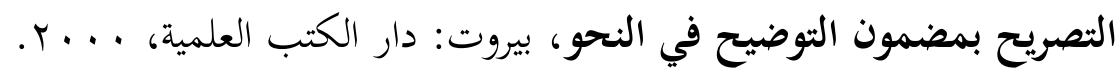

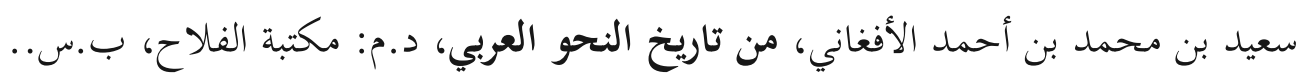

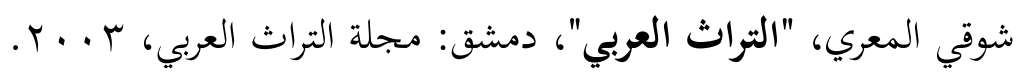

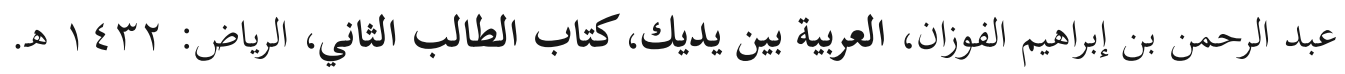

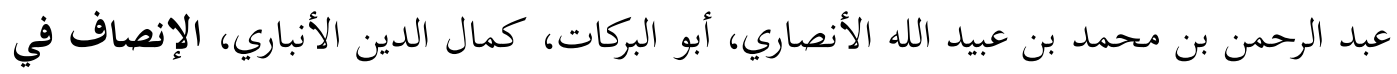

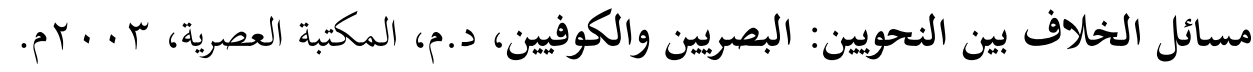

$$
\text { 9؛ أبو البركات، كمال الدين الأنباري، مرجع سابق،؛ ص. .9. }
$$


عبد الرحمن بن محمد بن قاسم العاصمي الحنبلي النجدي، حاشية الآجرومية، د. م، م •ـع . 2 .

عبد الله بن يوسف بن أحمد بن عبد الله ابن يوسف، أبو محمد، جمال الدين، ابن هشام، أوضح المسالك إلى ألفية ابن مالك، دار الفكر للطباعة والنشر والتوزيع، د.س.

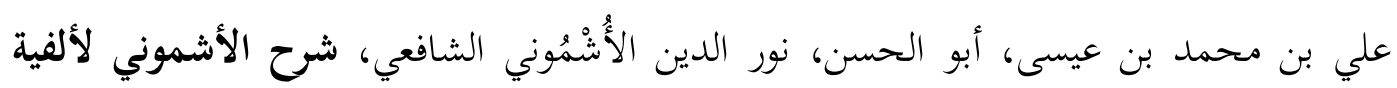

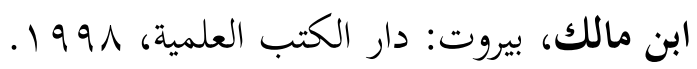

محمد بن عبد الله، ابن مالك الطائي الجياني، أبو عبد الله، جمال الدين، شرح الكافية الثافية، د.م. جامعة أم القرى مركز البحث العلمي وإحياء التراث الإسلامي، د.س. محمد بن علي بن أحمد بن عمر بن يعلى، أبو عبد الله، بدر الدين البعليّ، المنهج القويم في

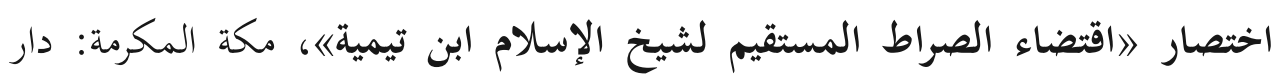

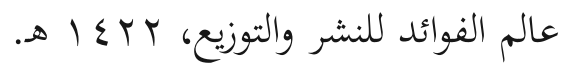
محمد عبد العزيز النجار، ضياء السالك إلى أوضح المسالك، د.م، مؤسسة الرسالة، ا ـ. ب بم. محمد عيد، النحو المصفى، د.م. مكتبة الشباب، د.س. مصطفى بن محمد سليم الغلايينى، جامع الدروس العربية، بيروت: المكتبة العصرية، بو9 1 هـ، $. \nmid \wedge . b$ مهدي المخزومي، مدرسة الكوفة ومنهجها في دراسة اللغة والنحو، بغداد: دار المعرفة، . 1900-ه ITVE

نبيهة بنت عبد الله باخشوين، أصول النحو وتاريخه، الرسالة، جامعة أم القرى، مملكة العربية السعودية. يوسف حسن عمر، شرح الرضي على الكافية، بنغازي: جامعة قان يونس، د.س. 